\title{
THE WEAR BEHAVIOR OF VARIOUS MONOLITHIC CERAMICS AFTER WEAR SIMULATION AGAINST HUMAN ENAMEL
}

\author{
Amira Mohamed Elsharkawy*
}

\begin{abstract}
Purpose: To evaluate and compare the surface roughness (SR), weight loss and volume loss of three monolithic ceramics; monolithic zirconia functional explore (f.explore), lithium disilicate glass ceramic (IPS.e. max CAD), and lithium silicate (Obsidian) and their wear effect on the natural enamel.
\end{abstract}

Materials and Methods Twenty four ceramic discs and twenty four natural tooth antagonists were used. Samples were divided according to ceramic materials into 3 groups $(n=8)$. Group I: f.explore, Group II: Obsidian, and Group III: IPS e.max CAD. SR, weight loss and volume loss of the discs and the enamel were verified before and after exposing the specimens to chewing simulator. Digital and Scanning electron microscopic evaluations were used.

Results: statistical differences in the SR changes among all groups were non-significant. The Obsidian antagonist cusp recorded the highest roughness followed by f.explore, whereas, e.max recorded the lowest value. The greatest mean material weight loss was recorded in the e.max group, followed by f.explore, whereas, the lowest was recorded for Obsidian group. The difference between the groups was statistically significant. The greatest mean antagonist cusp weight loss was recorded for f.explore followed by Obsidian, while the lowest antagonist weight loss was recorded in e.max group. The difference between the groups was statistically significant as indicated by ANOVA test $(\mathrm{p}=<0.0001<0.05)$. The greatest mean material volume loss was recorded in e. max followed by f.explore, whereas, Obsidian recorded the lowest value. The difference between the groups was statistically significant $(\mathrm{p}<0.05)$ as indicated by one way ANOVA test, Pair-wise Tukey's post-hoc test showed non-significant ( $\mathrm{p}>0.05$ ) difference between (f.explore and Obsidian) groups. The greatest mean antagonist cusp volume loss was recorded in f.explore followed by e.max whereas Obsidian antagonist group was recorded the lowest value. The difference between the groups was statistically significant $(\mathrm{p}<0.05)$ as indicated by one way ANOVA test. Pair-wise Tukey's post-hoc test showed non-significant $(\mathrm{p}>0.05)$ difference between (e.max and Obsidian) groups.

Conclusions: Obsidian is more wear resistant than e.max and f.explore and produced the least wear in opposing enamel.

KEYWORDS: Wear Behavior, Monolithic Ceramics, Wear Simulation, Human Enamel.

\footnotetext{
* Associate Professor, Fixed Prosthodontics, Faculty of Dentistry, $6^{\text {th }}$ of October University, Giza, Egypt
} 


\section{INTRODUCTION}

Tooth wear is defined as loss of a tooth structure due to a number of factors. Leading to several clinical complications as enamel loss, vertical dimension changes, temporomandibular complaints, hypersensitivity, and esthetic loss. ${ }^{(1)}$

The aim of restorative dentistry is to find the proper biocompatible substitute for hydroxyapatite. Full-contour CAD/CAM ceramic crowns are currently used as a relatively new restoration method in Prosthodontics. There are different types of CAD/ CAM block ceramic-glass-polymer materials ${ }^{(2)}$ with different compositions and physical properties: IPS empress leucite ceramic, e.max press lithium disilicate ceramic, lithium disilicate glass-ceramic, YTZP ceramic, glass ceramic, zirconia, lithium disilicate, nanoceramic, zirconia- reinforced lithium silicate ceramic (Vita Suprinity), and polymer infiltrated ceramic network (PICN) materials, also called hybrid ceramics or glass ceramic in a resin interpenetrating matrix (Vita Enamic). ${ }^{(3)}$

Lithium disilicate is one of the more widely used glass ceramics. It is made by the addition of lithium oxide to alumina-silicate glass to improve its mechanical properties. ${ }^{(4)}$ All ceramic lithium disilicate crowns have been effectively used for single crowns and multiple unit fixed partial dentures with high survival rates. ${ }^{(5)}$

Ceramics wear is different from metal or composite resin wear against enamel. Ceramics and enamel wears through a micro-fracture mechanism while the composite resins wear through fatigue and abrasion. ${ }^{(6)}$

Recently in the past few years, a new glass ceramic; lithium silicate based was announced under the name of Obsidian. The obsidian milling block has unique property of containing a very high percentage of ultra-nanometer size lithium silicate and lithium phosphate crystals. Obsidian milling blocks is brought in the partially crystalized phase, which is to be milled with CAD/CAM methods. ${ }^{(7)}$ As claimed by the manufacturer, Obsidian is a zirconia reinforced lithium silicate ceramic that contains $6 \%$ atomically dissolved zirconia incorporated in the glass matrix to provide high mechanical property. Zirconia is responsible for the fine- grained lithium silicate crystals nucleation. The high glass content offers the material excellent optical, high mechanical properties and superb polishability. ${ }^{(8)}$

Oxide ceramics, as zirconia, are widely used nowadays because of their high strength and improved load bearing property. Developments in the mechanical properties of zirconia are invented to distress the wear performance. ${ }^{(9)}$

Preferably, the wear of both restorative material and enamel should be similar. The complexity of the wear progress and its quantification in the oral cavity makes in vivo tooth wear studies difficult. Since, wear simulators have been recognized, developments in the simulator technology have allowed imitation of human mastication in in-vitro settings using precise loads and frictional forces. ${ }^{(8,9)}$

The aim of this in vitro study was to investigate and compare the SR, weight loss and volume loss of three monolithic ceramic materials; polycrystalline zirconia (f. explore), lithium silicate ( obsidian), and lithium disilicate (e. max) and their antagonistic human enamel before and after fatigue loading with thermocycling in a chewing simulator. The null hypotheses were that all the tested materials and their opposing enamel would display similar SR, weight loss, and volume loss values after the wear cycles.

\section{MATERIALS AND METHODS}

Materials used in this study are described in (Table 1). Twenty four ceramic disc specimens were made with dimensions of $10 \mathrm{~mm}$ diameter $\mathrm{x} 1.5 \mathrm{~mm}$ height. The disc specimens were divided according to the ceramic materials into three equal groups $(\mathrm{n}=8)$. Group I: F.explore (Shenzhen Upcera Dental 
Technology Co, China), group II: Obsidian (Glidewell Dental Laboratories, Newport Beach, CA, USA), and group III: E.max (Ivoclar Vivadent AG, Schaan, and Principality of Liechtenstein).

The sample size of 8 per group was selected as follows: at significance of 0.05 with estimated standard deviation, power and maximum difference of $0.3,0.96$, and 0.7 , respectively, the sample size for each group was supposed to be at least 8 . Previous studies ${ }^{(9,10)}$ also observed the sample size of 8 per group to be sufficient for wear studies using chewing simulation under standardized controlled environment.

A total of twenty four first premolars were selected for the current study. The selection criteria were based on teeth condition. All teeth were examined under 4x magnification loops (HEINE Optotechnik $\mathrm{GmbH} \& \mathrm{Co.KG}$ ) for any cracks, fractures, worn-out cusps, caries, or restorations. All defected teeth were excluded. The teeth were then splitted mesio-distally to use the buccal half only that was mounted to Jakub's chuck (of the chewing simulator) leaving only the buccal cusp exposed for testing process. All teeth were stored in distilled water at the room temperature until the tests were taking place and used as samples within thirty days after the extraction.

The tooth antagonist was fixed in upper Jackob's chuck in a tooth antagonist holder that can be tightened with a screw. For each of the three groups; the discs were then cleaned in an ultrasonic bath for $10 \mathrm{~min}$ and were inserted in a lower plastic sample holder specially designed with a round depression having the same dimensions of the specimen to be tested. (Figure 1A, B).

\section{Construction of Explore zirconia disc specimens:}

Eight discs with $10 \mathrm{~mm}$ diameter and $1.5 \mathrm{~mm}$ thickness were milled, and finished according to the manufacturer's guidelines.
For construction of f. explore samples, Virtual disc with dimensions $(10 \mathrm{~mm}$ diameter $\mathrm{x} 1.5 \mathrm{~mm}$ thickness was designed with EXOCAD Valetta 2.2 software library (Exocad $\mathrm{GmbH}$ ) and saved as the reference design ${ }^{(11)}$, pre-shaded (A3) f. explore discs were milled by using 4-axes milling unit (Roland Modified MDX 40, Japan) by Advanced Dental Studio - Egypt. The sintering process was preceded in the Tabeo high-temperature furnace (Mihm Vogt $\mathrm{GmbH}$, Germany) by using the preset program of F. Explore as recommended by the manufacturer. The finishing and polishing procedure was done using Zirconia finishing and polishing set; (Dialite ZR Zirconia Intra-Oral Adjustment/Polishing System, Brasseler, USA) following manufacturer instructions. The specimens were polished by using an electric contra angle hand-piece (NSK EX-6B, Japan). The hand piece was mounted to a special device to ensure standardization of grinding pressure, direction and rate to which the samples were subjected. All polishing procedures were carried out at a recommended speed of 8000 RPM. ${ }^{(12)}$ Each step was done for 1 minute. Medium and fine diamond polishing paste was used with a small round brush for 1minute with each grit. The discs were then washed in an ultrasonic bath for 10 minute and inserted in a lower plastic (Teflon) sample holder. (Figure 1B)

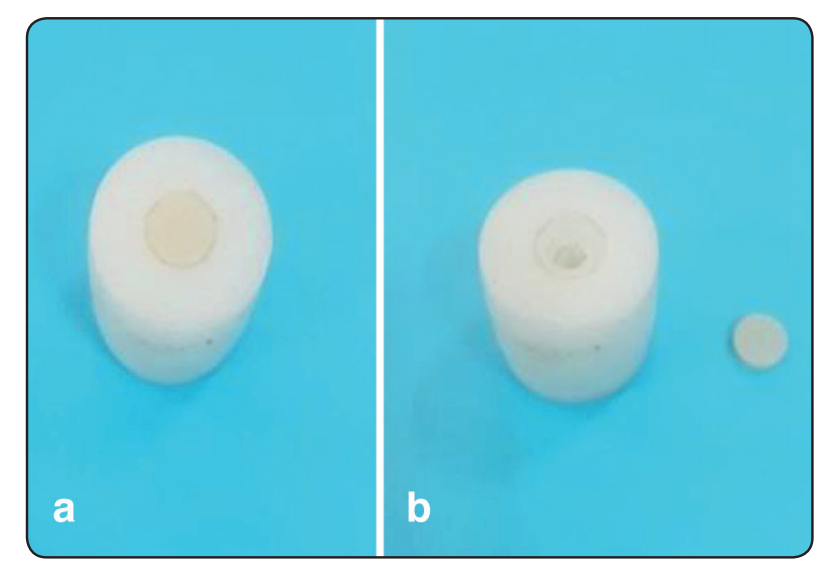

Fig. (1) (A) Disc shaped material specimen inserted in resin block.(B) 
TABLE (1) The test groups, abbreviations, brands, and manufacturers of the tested materials $(\mathrm{N}=24)$

\begin{tabular}{|c|c|c|c|c|}
\hline Test group & Brand & Abbreviation & Description, properties \& composition & $\begin{array}{l}\text { Manufacturers } \\
\text { informations }\end{array}$ \\
\hline \multirow[t]{2}{*}{$\begin{array}{c}\text { Monolithic } \\
\text { zirconia }\end{array}$} & $\begin{array}{c}\text { Functional } \\
\text { explore }\end{array}$ & f.explore $(n=8)$ & $\begin{array}{l}\text { Upcera Zirconia, specialized for Full Contour } \\
\text { Zirconia restorations Multi Layered Zirconia disc } \\
\text { with } 98.5 \mathrm{~mm} \text { diameter and } 18 \mathrm{~mm} \text { thickness, shade } \\
\text { A light Flexural strength: } 1125 \mathrm{MPa} \text { Fracture tough- } \\
\text { ness :5.1 MPa m² Elastic modulus : } 214 \mathrm{GPa} \text { Hard- } \\
\text { ness } 13.4 \mathrm{Composition} \text { in Wt\%: Zirconium dioxide } \\
\mathrm{ZrO} 2+\mathrm{HfO} 2 \text { 90-95\% Yttrium Oxide Y2O3 5-8 \% }\end{array}$ & $\begin{array}{l}\text { Shenzhen Upcera Dental } \\
\text { Technology Co, China }\end{array}$ \\
\hline & & & Other oxides $\mathrm{CaO}, \mathrm{MgO} 0-2 \%$ & \\
\hline $\begin{array}{l}\text { Monolithic } \\
\text { Lithium } \\
\text { silicate }\end{array}$ & Obsidian & $\begin{array}{l}\text { Obsidian } \\
(\mathrm{n}=8)\end{array}$ & $\begin{array}{l}\text { an innovative combination of more than } 20 \text { unique } \\
\text { elemental oxides, } \mathrm{SiO}_{2}-\mathrm{Li}_{2} \mathrm{O}-\mathrm{K}_{2} \mathrm{O}-\mathrm{Al}_{2} \mathrm{O}_{3}-\mathrm{ZrO}_{2}-\mathrm{P}_{2} \mathrm{O}_{5} \\
\text { including zirconia, }(4-6 \%) \text { Flexural strength }: 385 \\
\text { MPa Fracture toughness : } 2.56 \mathrm{MPa} \mathrm{m}^{1} / 2 \text { Elastic } \\
\text { modulus : } 76.46 \mathrm{GPa} \text { Hardness : } 6.5 \\
\text { Composition of the ceramic part Nanometer-sized } \\
\text { lithium silicate and lithium phosphate crystals with } \\
\text { Zirconia }\end{array}$ & $\begin{array}{l}\text { Glidewell Dental } \\
\text { Laboratories, Newport } \\
\text { Beach, CA, USA }\end{array}$ \\
\hline $\begin{array}{l}\text { Lithium } \\
\text { disilicate }\end{array}$ & $\begin{array}{l}\text { IPS E.max } \\
\text { CAD }\end{array}$ & e.max $(n=8)$ & $\begin{array}{l}\text { Lithium disilicate glass-ceramic block Flexural } \\
\text { strength : } 360 \mathrm{MPa} \\
\text { Fracture toughness: } 2.0-2.5 \text { Elastic modulus : } 95 \pm \\
5 \mathrm{GPa} \text { Hardness: } 5.8 \\
\text { Composition in } \mathrm{Wt} \% \text { : } \\
\text { Silicon dioxide } \mathrm{SiO} 257.0-80.0 \\
\text { Lithium dioxide Li2O } 11.0-19.0 \\
\text { Potassium oxide } \mathrm{K} 2 \mathrm{O} 0.0-13.0 \text { Phosphorus } \\
\text { pentoxide P2O5 } 0.0-11.0 \\
\text { Zirconium dioxide } \mathrm{ZrO} 20.0-8.0 \\
\text { Zinc oxide ZnO } 0.0-8.0 \\
\text { Other \& coloring oxides } 0.0-12.0\end{array}$ & $\begin{array}{l}\text { Ivoclar Vivadent AG, } \\
\text { Schaan, Principality of } \\
\text { Liechtenstein }\end{array}$ \\
\hline
\end{tabular}

\section{Construction of LD (e. max CAD) and lithium silicate (Obsidian) specimens:}

Disks specimens were prepared from each material using the CAD software (Dental CNC, v6.17.00). A design was created that suits the dimension of the milling blocks for both the obsidian and e-max. The CAD-CAM partially crystalized blocks were smoothed in an automatic orbital sander (Ecomet 250; buehler, lake Bluff, IL,USA) using water sandpaper with grain size \#600. Next, the roller were cut using a precision cutting machine (saw) (isomet 4000, Buehler, Germany) into disks to obtain discs with $10 \mathrm{~mm}$ diameter $\times 1.5 \mathrm{~mm}$ thickness of each ceramic specimen. Each ceramic disc thickness was checked by a caliper. A3 shade milling blocks were selected for the obsidian and e.max samples. Obsidian and e.max CAD discs were crystallized (Programat P310; Ivoclar Vivadent AG). ${ }^{(13)}$ Crystallization and sintering process were completed according to the manufacturers' directions. Regard to the polishing process, the specimens were polished by using the Dialite LD ExtraOral Polisher System (Brasseler, USA, following the manufacturer instruction. An electrical contra 
angle hand-piece (NSK EX-6B, Japan) was used. The hand piece was mounted to a special device to make sure standardization of grinding pressure, direction and rate to which the samples were subjected. All polishing procedures were carried out at a recommended speed of 8000 RPM. Each step was done for 1 minute. Medium and fine diamond polishing paste was used with a small round brush for 1 minute with each grit. The discs were then washed in an ultrasonic cleaner for $10 \mathrm{~min}$. and inserted in a lower plastic (Teflon) sample holder.

\section{Wear testing}

The wear simulation testing was performed using programmable equipment (four stations multimodal ROBOTA chewing simulator (Figure. 2) Incorporated with thermo-cyclic protocol operated on servo-motor (Model ACH-09075DC-T, AD-Tech Technology CO., LTD., Germany). The chewing simulator has four chambers simulating the vertical and horizontal movements simultaneously in the thermodynamic condition. Each of the chambers consists of an upper Jackob's chuck as tooth antagonist container that can be tightened with a screw and a lower Teflon sample holder in which the disc can be inserted. The teflon holder is fixed in the lower chamber that contains distilled water to be used during testing procedures. All groups samples (f. explore, obsidian and e.max and their corresponding teeth specimens) were mounted and tested sequentially. A load of $5 \mathrm{~kg}$, comparable to 49 $\mathrm{N}$ of grinding force was used. The strokes repeated 75.000 cycles masticatory movements condition associated the thermo-cycling with distilled water, under the wear testing parameters mentioned in (Table 2). Surface Roughness (SR), volume loss and weight loss were determined before and after exposing the specimens to wear cycles. Digital microscopic qualitative evaluations were recorded for the specimens and the opposing enamel before and after testing. All specimens were also examined under a scanning electron microscope (SEM) before and after the wear cycle. The specimens were sputtercoated with gold (S150 A sputter couture-Edwards) under vacuum and examined by a (SEM) (Quanta FEG250. Japan) operating at $20.0 \mathrm{Kv}$, at $3000 \mathrm{X}$. ${ }^{(14)}$

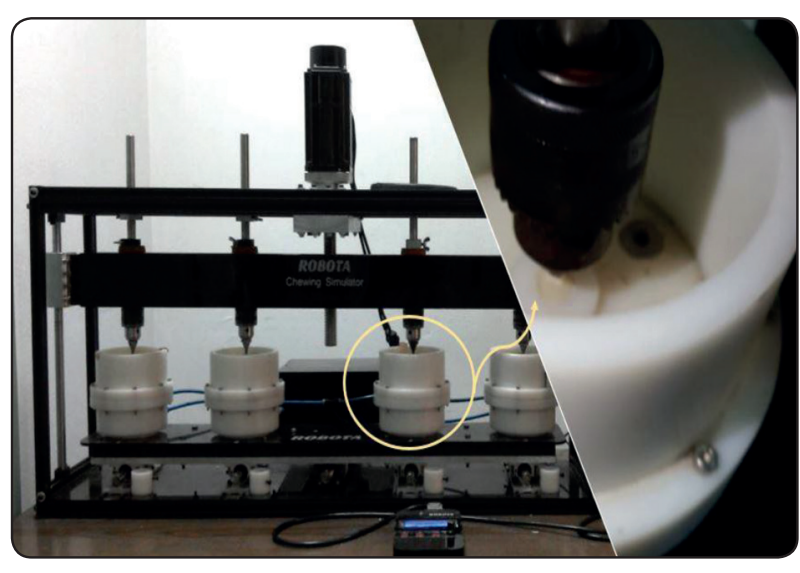

Fig. (2) Chewing simulator with tooth-material assembly in place

TABLE (2): Wear simulation testing parameters:

\begin{tabular}{|c|c|}
\hline \multicolumn{2}{|c|}{ Wear test parameters } \\
\hline $\begin{array}{c}\text { Cold/hot bath temperature: } \\
5^{\circ} / 55^{\circ}\end{array}$ & Dwell time: $60 \mathrm{~s}$ \\
\hline Vertical movement: $1 \mathrm{~mm}$ & Horizontal movement: $3 \mathrm{~mm}$ \\
\hline Rising speed: $90 \mathrm{~mm} / \mathrm{s}$ & Forward speed: $90 \mathrm{~mm} / \mathrm{s}$ \\
\hline Descending speed: $40 \mathrm{~mm} / \mathrm{s}$ & Backward speed: $40 \mathrm{~mm} / \mathrm{s}$ \\
\hline Cycle frequency $1.6 \mathrm{~Hz}$ & Weight per sample: from \\
$5 \mathrm{~kg}$
\end{tabular}

\section{Analysis of Parameters}

\section{Surface Roughness Analysis:}

The optical profilometry is able to accomplish the quantifiable characterization of surface topography without contact. Quantifiable analysis of the wear simulation on the discs and their antagonists was showed before and after loading in a 3D-surface analyzer system. Specimens were snapped using USB Digital microscope with a built-in camera (Scope Capture Digital Microscope, Guangdong, China) linked with an IBM compatible personal 
computer using a fixed magnification of $120 \mathrm{X}$. The images were recorded with a resolution of $1280 \times$ 1024 pixels per image. Digital microscope images were cropped to $350 \times 400$ pixels using Microsoft office picture manager to specify/standardize area of roughness measurement. ${ }^{(15)}$

The cropped images were examined using WSxM software. Within the WSxM software, all limits, sizes, frames and measured parameters are expressed in pixels. Therefore, system calibration was done to convert the pixels into absolute real world units. Calibration was made by comparing an object of known size (a ruler in this study) with a scale generated by the software. WSxM software was used to calculate average of heights ( $\mathrm{Ra}$ ) expressed in $\mu \mathrm{m}$, which can be presumed as a reliable indices of surface roughness. ${ }^{(16)}$

Subsequently, a 3D image of the surface profile of the specimens was generated using a digital image analysis system (Image J 1.43U, National Institute of Health, USA). The unworn surface worked as a reference. With this method, a 3-dimensional geometry of the worn surface was created.

\section{Weight loss measurement:}

Weight measurements for all samples were measured for quantitative loss before and after the wear cycles. The material loss of the samples after testing was measured by weighting in the electronic analytical balance (Sartorius, Biopharmaceutical and Laboratories, Germany) with an accuracy of 0.0001 gram (Figure 3) to weight the difference in weight before and after 75.000 cycles. As this electronic balance had a fully automated calibration technology and a micro weighing scale, values of all the mounted discs and antagonist samples were accurately measured. Each mounted sample was cleaned and dried with tissue paper before weighing. To confirm precision, the balance was retained on a free standing table the specimens were weighed with the door of the balance closed to avoid air drafts effect.

\section{Three-Dimensional Volume Loss Analysis:}

The surface of each specimen and enamel antagonist were scanned (U500X, Digital Microscope, Guangdong, China) with a $10 \mu \mathrm{m} \times 10 \mu \mathrm{m}$ resolution; before and after wear testing. The scans were analysed with WSXM software (Ver 5 develop 4.1, Nanotec, Electronica, SL) to determine volume wear. ${ }^{(17)}$

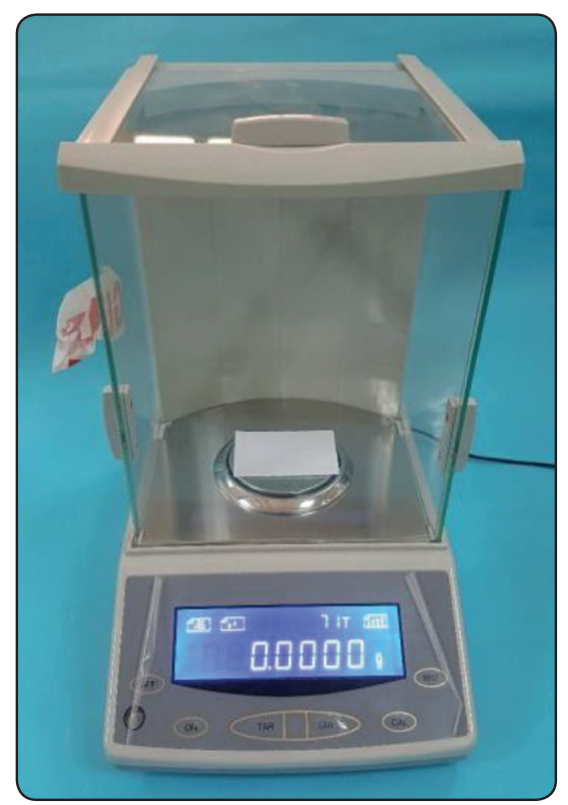

Fig. (3) Electronic analytical balance.

\section{Scanning electron microscope (SEM):}

For characterizing wear patterns, one illustrative ceramic disc from each group (before and after two-body wear test) was selected for SEM using the FEI Quanta 250 FEG-SEM (FEI COMPANY, Nederland), the discs were sputter- coated with gold under vacuum and examined using SEM at a x3000 magnification operating at $20.00 \mathrm{kV}$.

\section{Statistical Analysis}

Statistical analysis was performed using GraphPad InSat statistics software for Windows (www. graphpad.com. Within group comparison (before and after wear simulation) was carried out using 
Student t-test. Between group comparison was done using One-way ANOVA followed by Tukey's post-hoc (if displayed significant) between wear changes. $\mathrm{P}$ values $\leq 0.05$ are considered statistically significant.

\section{RESULTS}

\section{I- Surface Roughness changes}

The mean values and standard deviations (SD) for surface roughness measured by average heights in $(\mu \mathrm{m})$ recorded on all materials groups before and after 6 months wear simulation cycles are shown in Table 3 and in Figure 4. Mean surface roughness

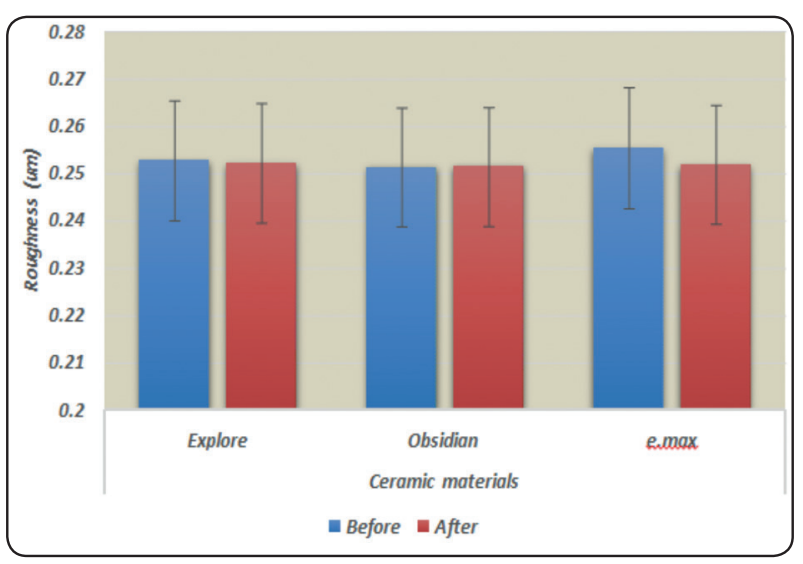

Fig. (4) Column chart showing surface roughness mean values for all materials before and after 6 months wear simulation cycles. values increased slightly after wear simulation in f.explore and Obsidian groups and slightly decreased in the e.max group. However these differences were statistically insignificant ( $>$ > 0.05) within each group as well as among the three material groups.

\section{In enamel antagonist groups}

The mean values and SD for antagonist enamel cusp SR measured by $(\mu \mathrm{m})$ recorded on all material groups before and after 6 months are shown inTable 4 and in Figure 5.

Mean surface roughness values decreased in Obsidian antagonist cusp followed by f.explore and increased in e.max group. The difference between

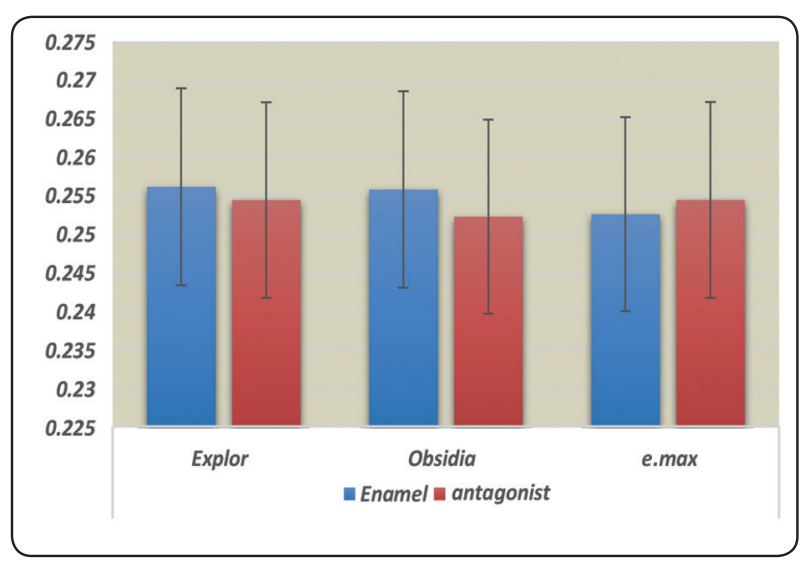

Fig. (5) Column chart showing surface roughness mean values for materials antagonistic enamel cusp before and after 6 months wear simulation cycles.

TABLE (4) The mean values and standard deviations (SD) for surface roughness for materials antagonistic enamel cusp before and after 6 months wear simulation cycles:

\begin{tabular}{|c|c|c|c|c|c|}
\hline \multirow{2}{*}{ Variables } & \multicolumn{3}{|c|}{ Antagonistic enamel cusp } & \multicolumn{2}{c|}{ Statistics } \\
\cline { 2 - 7 } & Before & After & Change & t-value & P value \\
\hline f.explore antagonist & $0.256175 \pm 0.004692$ & $0.25446 \pm 0.002547$ & $0.001708 \pm 0.003449$ & 0.96 & $0.1757 \mathrm{~ns}$ \\
\hline Obsidianantagonist & $0.255833 \pm 0.001087$ & $0.2523 \pm 0.000909$ & $0.003533 \pm 0.001948$ & 7.5 & $<0.0001 *$ \\
\hline e.max antagonist & $0.252633 \pm 0.001457$ & $0.254475 \pm 0.00184$ & $-0.00184 \pm 0.002578$ & 2.4 & $0.0159 *$ \\
\hline ANOVA & \multicolumn{2}{|c|}{ F-value } & & \multicolumn{3}{|c|}{0.03} \\
\cline { 2 - 6 } & \multicolumn{2}{|c|}{ P value } & & $0.0012^{*}$ \\
\hline
\end{tabular}


roughness changes recorded for groups antagonistic enamel cusp was statistically significant as indicated by ANOVA test $(\mathrm{p}=0.0012)$. Tukey's test results revealed that there was a statistically significant difference between the three groups. E.max antagonist showed the highest value (increase in roughness). F.explore antagonist showed statistically significantly lower mean value. Obsidian antagonist showed the statistically significantly lowest mean decrease in surface roughness.

\section{Wear results by weight changes:}

\section{Weight loss of ceramic materials:}

The mean values and standard deviations (SD) for weight loss measured in grams ( $\mathrm{Gr}$ ) before and after 6 months wear simulation cycles are summarized in Table (5) and graphically represented in Figure (6).

All materials tested showed some weight loss after wear simulation. However these changes were statistically insignificant within each group. The greatest mean weight loss was recorded for the e. max group, followed by f.explore, where the lowest weight loss was recorded for the obsidian group. The difference between weight changes recorded for materials was statistically significant as indicated by ANOVA test $(\mathrm{p}=<0.0001<0.05)$. According to Tukey's test results, there was a statistically significant difference between the three groups. E.max showed the highest mean wear

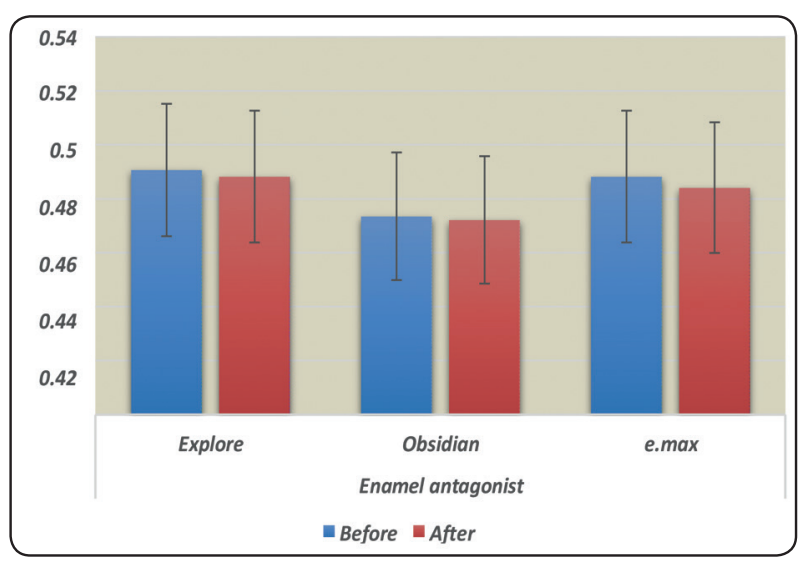

Fig. (6): Column chart showing weight mean values for all materials before and after 6 months wear simulation cycles.

value. F.explore showed statistically significantly lower mean wear. Obsidian showed the statistically significantly lowest mean wear.

\section{Weight loss for the antagonistic enamel cusp:}

The mean values and standard deviations (SD) for weight loss measured in grams (Gr) before and after 6 months wear simulation cycles are summarized in Table (6) and graphically represented in Figure (7).

All antagonist cusps in all three groups showed some weight loss after wear simulation. However these changes were statistically insignificant within each group. The difference between weight changes recorded for materials antagonistic enamel cusps

TABLE (5): The mean values and standard deviations (SD) of weight results for all materials before and after 6 months wear simulation cycles

\begin{tabular}{|c|c|c|c|c|c|}
\hline \multirow{2}{*}{ Variables } & \multicolumn{3}{|c|}{ Weight results } & \multicolumn{2}{c|}{ Statistics } \\
\cline { 2 - 6 } & Before & After & Change & t-value & P value \\
\hline f.explore & $0.490658 \pm 0.080875$ & $0.48815 \pm 0.080662$ & $0.002508 \pm 0.00127$ & 0.066 & $0.4741 \mathrm{~ns}$ \\
\hline Obsidian & $0.473444 \pm 0.088375$ & $0.4721 \pm 0.087992$ & $0.001344 \pm 0.000457$ & 0.03 & $0.4873 \mathrm{~ns}$ \\
\hline e.max & $0.488158 \pm 0.081602$ & $0.48405 \pm 0.085113$ & $0.004108 \pm 0.000985$ & 0.11 & $0.4590 \mathrm{~ns}$ \\
\hline ANOVA & \multicolumn{2}{|c|}{ F-value } & & \multicolumn{3}{|c|}{$<0.0001 *$} \\
\cline { 2 - 6 } & \multicolumn{2}{|c|}{ P value } & \multicolumn{3}{c}{} \\
\hline
\end{tabular}

\footnotetext{
*; significant $(p<0.05) \quad n s ;$ non-significant $(p>0.05)$
} 
groups was statistically significant as indicated by ANOVA test ( $\mathrm{p}=0.0223<0.05)$. Pair-wise Tukey's post-hoc test showed non-significant $(\mathrm{p}>0.05)$ difference between (f.explore and Obsidian) groups . The greatest mean weight loss for antagonist cusp was recorded for f.explore followed by obsidian, while the lowest weight loss was recorded in e.max antagonist cusp with a statistically significant difference from f.explore and Obsidian.

\section{Volume loss results:}

\section{Volume loss of material:}

The average values and standard deviations (SD) for wear test measured by volume loss $\left(\mu \mathrm{m}^{3}\right)$ recorded on all experimental groups before and after 75.000 wear simulation cycles as shown in Table (7) and Figure (8).

The greatest mean was recorded in e. max followed by f.explore. The difference between groups regarding to volume loss was statistically significant $(\mathrm{p}<0.05)$ as indicated by one way ANOVA test, whereas the lowest volume loss was recorded in Obsidian. Pair-wise Tukey's post-hoc test showed non-significant $(\mathrm{p}>0.05)$ difference between (f.explore and Obsidian) groups.

\section{Volume loss of antagonist cusp}

The average values and standard deviations (SD) for wear test measured by volume loss $\left(\mu \mathrm{m}^{3}\right)$ before and after 75000 simulation cycles are summarized in Table 8 and graphically represented in Figure 12.

\section{Enamel antagonist volume loss results:}

The greatest mean of volume loss of antagonist was recorded in f.explore followed by e max antagonist cusp; where the lowest volume loss was recorded in obsidian antagonist cusp; the difference among the three groups was statistically significant $(\mathrm{p}<0.05)$ as indicated by one way ANOVA test. TABLE (6) The mean values and standard deviations (SD) for weight results for all antagonist enamel cusp before and after 6 months wear simulation cycles:

\begin{tabular}{|c|c|c|c|c|c|}
\hline \multirow{2}{*}{ Variables } & \multicolumn{3}{|c|}{ Samples } & \multicolumn{2}{c|}{ Statistics } \\
\cline { 2 - 7 } & Before & After & Change & t-value & P value \\
\hline f.explore & $0.979458 \pm 0.004894$ & $0.979067 \pm 0.004854$ & $0.000392 \pm 0.000431$ & 0.1704 & $0.4334 \mathrm{~ns}$ \\
\hline Obsidian & $0.186167 \pm 0.00368$ & $0.185844 \pm 0.003619$ & $0.000322 \pm 0.000123$ & 0.1873 & $0.4269 \mathrm{~ns}$ \\
\hline e.max & $0.164317 \pm 0.027161$ & $0.164283 \pm 0.027143$ & $0.000033 \pm 0.000131$ & 0.003 & $0.4990 \mathrm{~ns}$ \\
\hline \multirow{2}{*}{ ANOVA } & \multicolumn{3}{|c|}{ F-value } & \multicolumn{3}{|c|}{4.47} \\
\cline { 2 - 7 } & \multicolumn{3}{|c|}{ P value } & \multicolumn{3}{c}{$0223^{*}$} \\
\hline
\end{tabular}

*; significant $(p<0.05) \quad n s ;$ non-significant $(p>0.05)$

TABLE (7) Volume loss results of three ceramic materials (Mean values \pm SD)

\begin{tabular}{|c|c|c|c|c|c|}
\hline \multirow{2}{*}{\multicolumn{2}{|c|}{ Variables }} & \multicolumn{3}{|c|}{ volume results } & \multirow{3}{*}{$\begin{array}{c}\text { t-test } \\
\text { P value } \\
0.85 \mathrm{~ns}\end{array}$} \\
\hline & & Before & After & Volume loss & \\
\hline \multirow{3}{*}{$\begin{array}{c}\text { Experimental } \\
\text { groups }\end{array}$} & f.explore & $0.001316 \pm 0.00017$ & $0.001395 \pm 0.0001$ & $-0.00007^{\mathrm{B}} \pm 0.00025$ & \\
\hline & Obsidian & $0.002297 \pm 0.0018$ & $0.001032 \pm 0.0004$ & $0.001264^{\mathrm{B}} \pm 0.00142$ & $0.04 *$ \\
\hline & e.max & $0.000812 \pm 0.00047$ & $0.002868 \pm 0.0021$ & $-0.00206^{\mathrm{A}} \pm 0.0022$ & $0.0278 *$ \\
\hline ANOVA & $P$ value & \multicolumn{3}{|c|}{$0.0026^{*}$} & \\
\hline
\end{tabular}

Different letters in one column showing significant $(p<0.05)$

*; significant $(p<0.05)$ 


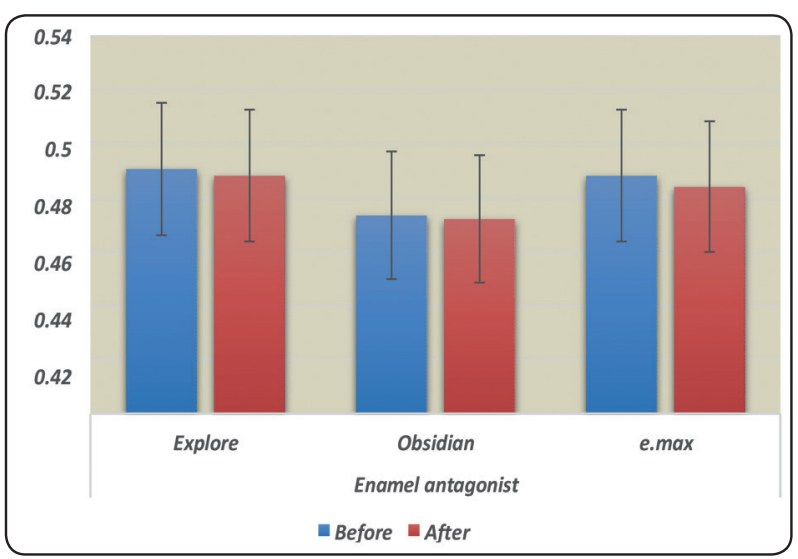

Fig. (7) Column chart showing weight mean values for antagonist enamel cusp before and after 6 months wear simulation cycles.

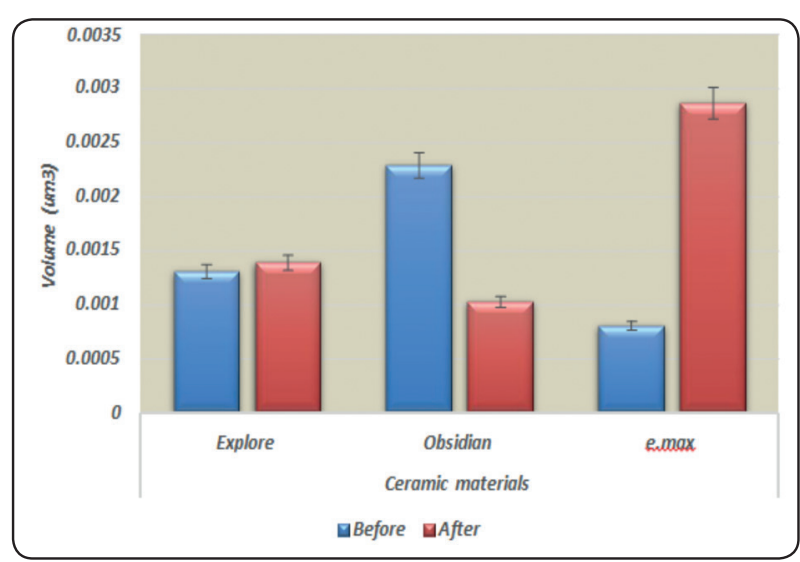

Fig. (8) Column chart showing volume mean values for experimental groups before and after wear simulation

TABLE (8) Volume loss of enamel antagonist cusp for the three ceramic groups:

\begin{tabular}{|c|c|c|c|c|c|}
\hline \multirow{2}{*}{\multicolumn{2}{|c|}{ Variables }} & \multicolumn{3}{c|}{ Volume results } & t-test \\
\cline { 3 - 7 } & Before & After & Volume loss & P value \\
\hline \multirow{3}{*}{$\begin{array}{c}\text { Enamel } \\
\text { antagonist }\end{array}$} & f.explore & $0.00466 \pm 0.00065$ & $0.001366 \pm 0.0002$ & $-0.00329 \pm 0.0008$ & $<0.0001 *$ \\
\cline { 2 - 7 } & Obsidian & $0.001366 \pm 0.00015$ & $0.001308 \pm 0.00018$ & $0.00005 \pm 0.00027$ & $0.5191 \mathrm{~ns}$ \\
\cline { 2 - 7 } & e.max & $0.002678 \pm 0.00238$ & $0.003342 \pm 0.0022$ & $-0.00066 \pm 0.0025$ & $0.2972 \mathrm{~ns}$ \\
\hline ANOVA & P value & & $0.0003 *$ & & \\
\hline
\end{tabular}

ns: non significant*; significant $(p<0.05)$

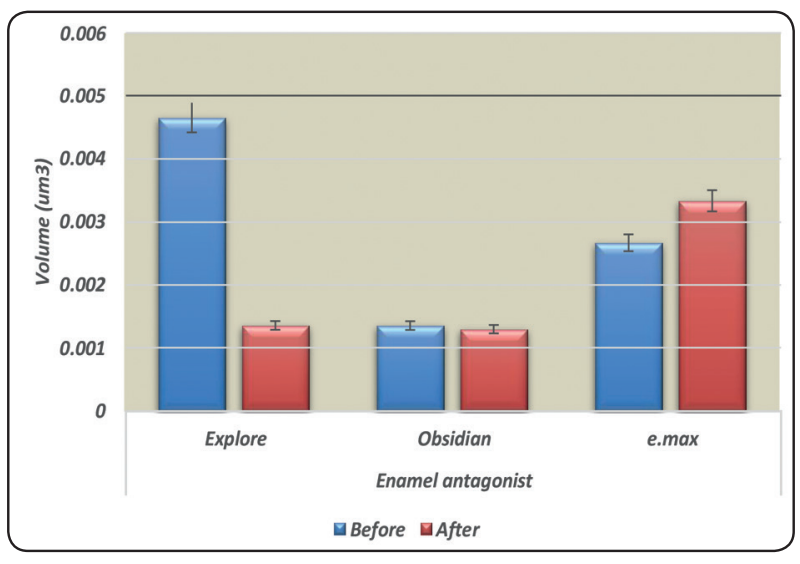

Fig. (9) Column chart showing volume mean values for enamel antagonist groups before and after wear simulation
Pair-wise Tukey's post-hoc test showed nonsignificant ( $p>0.05)$ difference between (e.max and Obsidian) groups.

\section{Scanning Electron microscope analysis}

SEM analysis of f.explore, obsidian and e.max ceramic surfaces before the two body wear test are presented in figures 16a, 17a, 18a. SEM photomicrographs of all ceramic surfaces show striations which indicate the direction of polishing. After twobody wear test; SEM photo- micrographs of worn surfaces of all tested ceramics reveal that the wear pattern was more evident in LD and obsidian discs (Figures17b, 18b) than explore (Figure 16b). 


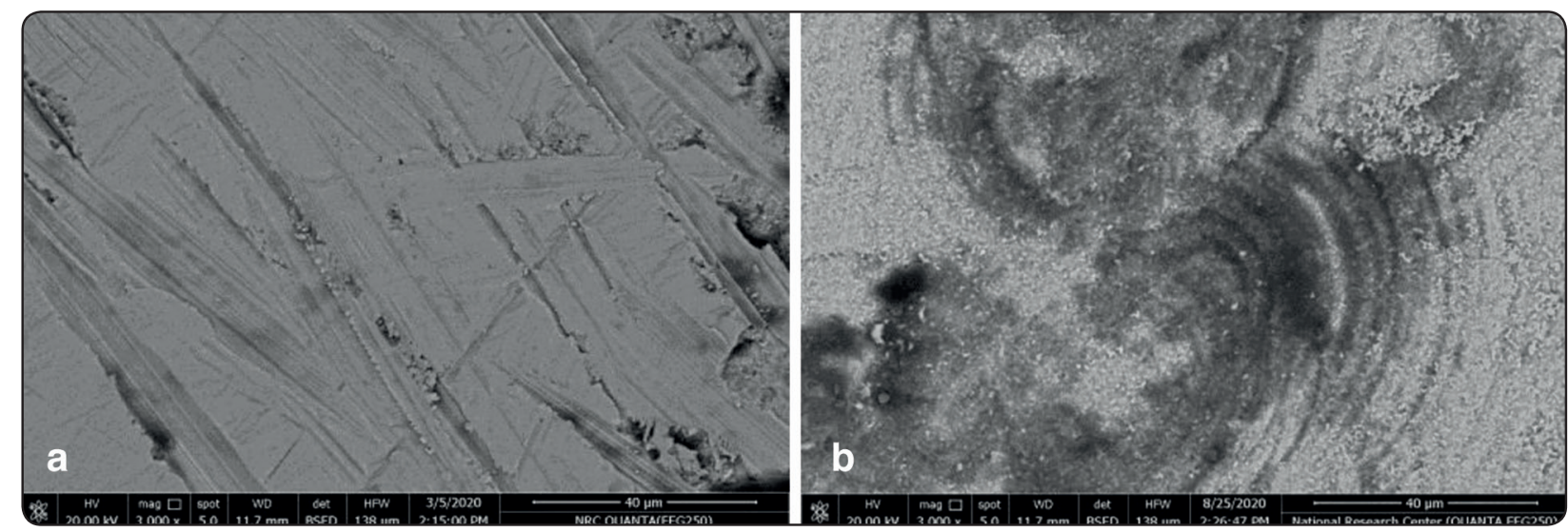

Fig. (10) SEM images of f.explore (Magnification 3000x; a: before wear test the surface shows shallow parallel striations. b: after wear test the worn surface shows shallow circular parallel striations .

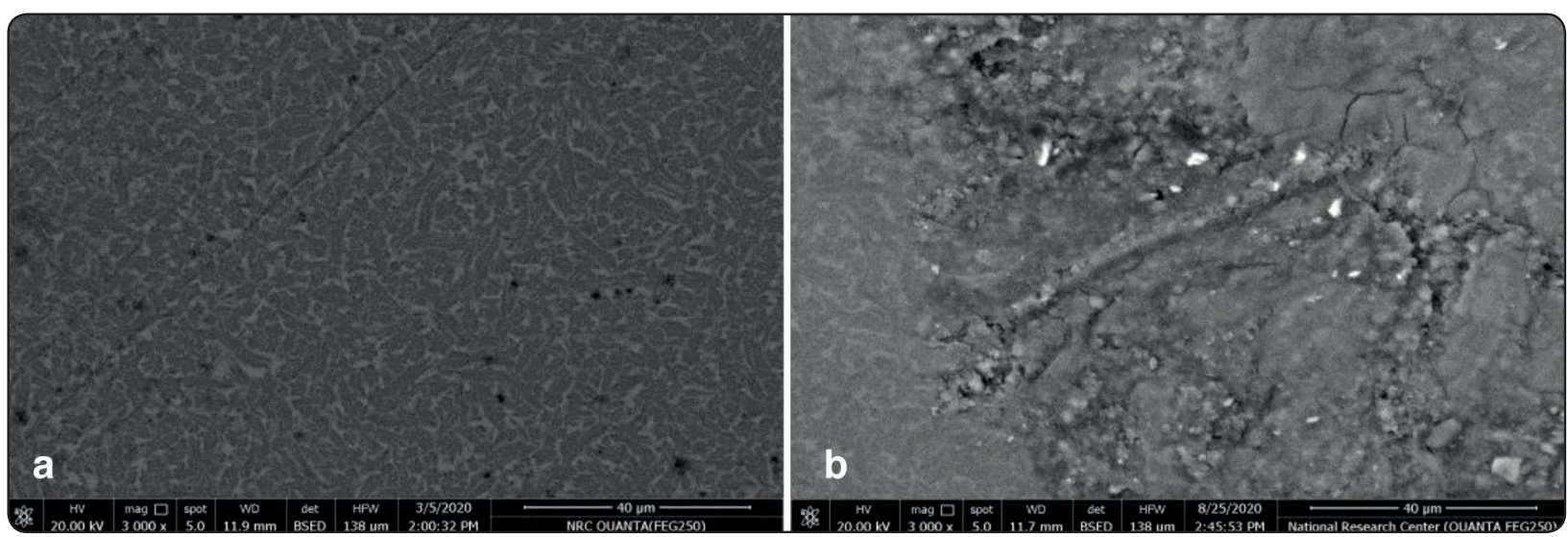

Fig. (11) SEM images of Obsidian (Magnification 3.000x; a: before wear test. b: after wear test the surface shows pulling out some of the grains/crystals.

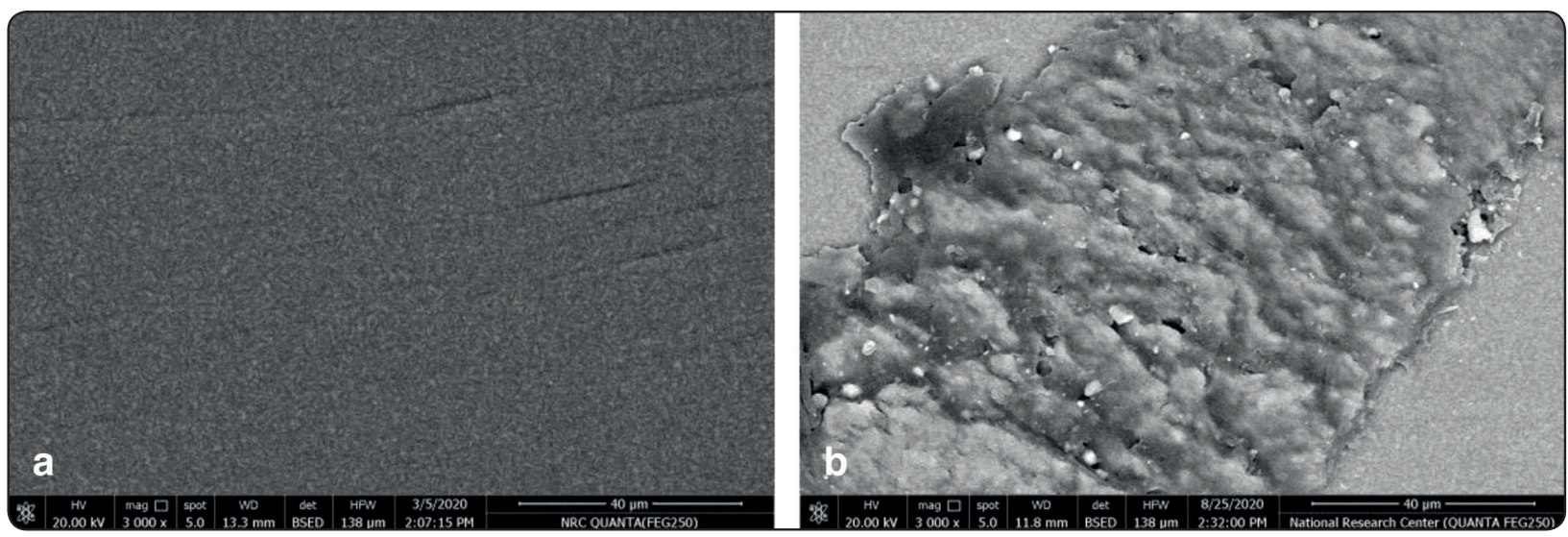

Fig. (12) SEM images of E. Max CAD (Magnification 3.000x; a before wear test the surface shows striations. $b$ after wear test the worn surface shows very deep furrows and subsidiary grooves which are parallel to one another. 


\section{DISCUSSION}

According to the results of the existing study, insignificant differences in the SR for the materials were detected. In contrast, the antagonist enamel samples presented significant roughness changes against each cermic material. Thus based on the results, the null hypothesis of no wear difference among the materials after the wear simulation was accepted and the null hypothesis of no wear difference of their opposing enamel was rejected.

The recent improvement of novel and efficient dental ceramic restorative materials has made possible for development in the biocompatibility and wear features of full ceramic CAD/CAM crowns. (18) The reliability of in vitro and clinical studies are very important. The arrangement of the in vitro study that consists of flat polished ceramic specimens and prepared enamel from extracted pre- molars as the antagonist is the most appropriate method to evaluate a ceramic material with respect to the antagonist wear. ${ }^{(19)}$

The two common types of wear in the oral cavity include the attrition wear and the abrasive type of wear or the combination of both. These two types of wear are of the greatest importance when a new restorative material is used. The antagonist enamel wear depends on the ceramic material and its fracture toughness, internal porosities, and surface defects. ${ }^{(20)}$

Enamel varies in its properties depending on tooth position and its histological structure. ${ }^{(41)}$ Cuspal enamel is stronger to withstand forces in a parallel direction to the enamel rods. Hence, in this study, freshly extracted non-attired, non-carious premolars of young adolescent patients undergoing orthodontic extractions were used. Since this study was to observe the wear behavior of enamel in a clinical atmosphere, only the cuspal tips of the dental specimens were held in contact with the ceramic specimens. ${ }^{(21)}$

In the present study, using a 3D profilometer for calculating the SR gives good resolution of the surface and has been described to be the best method for SR measurements by several authors. ${ }^{(22)}$
In this in vitro study, wear of enamel opposed to different ceramic materials was imitated to the oral environment using a wear machine. Two-body wear machine provided a combined action of impact, followed by sliding that matches the normal closure during mastication of the mandibular teeth onto the maxillary teeth for a total of 75,000 cycles to clinically simulate six -months. ${ }^{(23)}$ A weight of $5 \mathrm{~kg}$ (49 $\mathrm{N}$ ), which is equal to average chewing force, was applied onto the specimens. ${ }^{(24)}$

It was reported that polished ceramic surfaces have smoothness equal to or exceed that accomplished with surface glazing. ${ }^{(25)}$ It has also been reported that the glaze layer is usually wiped out within the earliest six months after restoration cementation exposing the deeper layers. ${ }^{(26)}$

All Tested materials received a polishing procedure which aimed to reach similar degree of baseline surface roughness. This process was reported by Amer et al ${ }^{(27)}$ who recommended standardization of the initial roughness values of all samples, irrespective of the finishing method used.

Wear was quantified in the present study built on the amount of weight loss and volume loss. Calculations of volume loss and weight loss were among the commonly used methods. ${ }^{(28)}$ However, Heintze et al (29) tested different methods used for the quantification of the in vitro wear of dental materials and found that all measuring principles were meet for the quantification of the wear created on flat samples.

As mentioned earlier, there were no significant differences between roughness changes recorded after chewing simulation for the three materials tested. Similar results were reported by Matzinger et al. ${ }^{(12)}$ whom did not find SR difference between zirconia reinforced lithium silicate (ZLS) and lithium disilicate (LD) after chewing simulation. The authors stated that the small differences in roughness between the materials highlighted the high efficiency of high-gloss lab-side polishing, although the materials presented individual surface roughness after milling although identical burs were used 
for milling. Differences in surface roughness after milling may depend on individual material properties. ${ }^{(30)}$ The results of the present study could also be attributed to the use of the Shofu polishing kit along with a diamond polishing paste for finishing LD and Obsidian and the silicon polishers for explore zirconia which can create a smooth surface finish comparable to that of a glazed one as claimed by several studies..$^{(31-33)}$

The results of the present study indicated that the obsidian produced the highest opposing enamel surface roughness followed by f.explore with insignificant difference between them. While e. max displayed the least SR of opposing enamel. The same findings were stated by Lohbauer and Reich ${ }^{(33)}$ in their recent research. This could be correlated to their hardness. The surface hardness value of zirconia (1250 HV) is extremely high and will cause more abrasion of the antagonist enamel. ${ }^{(34)} \mathrm{On}$ the other side the highest roughness recorded by obsidian could be attributed to the complex microstructure of zirconium-lithium ( $\mathrm{Li2O}-\mathrm{ZrO} 2-\mathrm{SiO} 2)$ silicates glass-ceramics which composed of glass and the crystalline structure. Crystalline phases composed of Nanometer-sized lithium silicate and lithium phosphate crystals with Zirconia exposed $\mathrm{ZrO} 2$ particles, functioned as an abrasive and made deep surface grinding tracks. ${ }^{(12)}$ This zirconia particles plow and deform the enamel surface and sponsored higher fracture toughness values comparing with lithium disilicate glass-ceramics. ${ }^{(31,32)}$ Moreover in a previous study conducted by Matziger et al; ${ }^{(12)}$ they found pores, grooves and superficial defects in the SEM picture for zirconia reinforced lithium silicate; their explanation was that these pores occur due to the presence of highly soluble crystals ( Lithium phosphate) which are removed during adjustment. This wear is influenced by material's properties such as fracture toughness, hardness and composition. With the continuing wear progression, the roughened ceramic surface causes persistent wear on the antagonist surface. ${ }^{(35)}$
Regarding the material loss after chewing simulation; E.max samples showed the statistically significant highest volume and weight loss while f. explore and Obsidian showed the statistically significant lowest material loss suggesting that zirconia was the most resistant material to wear degradation. This result is in accordance with other studies, ${ }^{(36-38)}$ in which zirconia proved to be resistant to loss by wear when it was compared to different restorative materials. Their explanation was that polycrystalline ceramics as zirconia show superior wear resistance as compared to low crystalline content ceramics. Hence, the possible explanation for the greater wear of e.max CAD compared to f. explore is that zirconia is less susceptible to the micro-fracture mechanism than glass ceramic because of the much higher fracture resistance of zirconia. The fracture toughness of the material is a key to the prevention of cracking. ${ }^{(39)}$ Consequently, under the same condition of wear process, the microcrack is probably more difficult to propagate through the crystalline structure of zirconia compared to e.max CAD. ${ }^{(40)}$ These findings are in agreement with those reported by several authors ${ }^{(41-43)}$ who found that; amount of wear of lithium di-silicate was greater than that of zirconia. Albasharieh et al ${ }^{(44)}$ found that zirconia samples verified significantly lower vertical and volumetric loss than nano-fluorapaptite and lithium di-silicate glass ceramics. SEM analysis verified our results as the wear patterns of e.max were more evident than f.explore. While obsidian shows shallowest striations this could be attributed to an innovative combination of more than 20 unique elemental oxides, including zirconia. The Obsidian formulation owes its excellent properties to a very high content of ultrafine, nanometer-sized lithium silicate and lithium phosphate crystals. Obsidian samples showed the statistically significant lowest volume and weight loss than E.max samples. This was in consistence with Paulo $\mathrm{j}$ et al ${ }^{(45)}$ who found that Lithium disilicate was more susceptible to wear with greater loss of volume and generated defect depth compared to the zirconia reinforced lithium 
silicate under the same conditions. The reason behind such results could be that the elastic modulus of the restorations is also a factor correlated with the stress concentration on the surface in response to the applied occlusal forces as the Obsidian presents a smaller elastic modulus than the e. max.

Additionally, Dal Piva et al. ${ }^{(46)}$ stated that ZLS has a lower risk of mechanical failure than the LD, which corroborates the findings of the present study. The result of the current study comes in agreement with Matzinger et al ${ }^{(12)}$ and Lawson et al. ${ }^{(47)}$ who compared the wear of several dental materials submitted to sliding chewing simulation in a similar device to that used in this study. They found that LD had approximately $33 \%$ more volume loss than ZLS, The authors reported that the lower elastic modulus and higher hardness for the ZLS, would justify the smaller volume loss in comparison to the LD. The SEM findings corroborates that previous investigation, ${ }^{(12)}$ which showed the same defect pattern generated on the discs surface after chewing simulation. The lowest volume loss of Obsidian could be attributed to the nano- and micron-sized crystals of lithium silicate glass-ceramic (50-60 percent $\mathrm{SiO} 2$, Nano-particles) and lower porosity of pressed monolithic ceramic as demonstrated by several investigators; ${ }^{(48-49)}$ they clarified that microstructural parameters, such as grain size and porosity, are essential agents in the wear process. Zum et $\mathrm{al}^{(50)}$ showed that a decrease in the ceramic's grain size causes an increase in its wear resistance. Additionally, it was concluded that grain size and porosity are two important microstructural features which may influence the mechanical and tribological properties of the ceramic. ${ }^{(51)}$

In the present study, decrease in the weight after two-body wear test in all ceramic materials, is likely to be attributed to the fact that wear process occurs whenever two surfaces interact with one another, causing loss of substance from the surfaces of materials. These results were in consistence with Albashaireh et al ${ }^{(44)}$ and Mundhe et al. ${ }^{(52)}$ they clarified that when ceramics slide against enamel, wear occurs by micro- fracture. They further explained that glass ceramics wear is mostly of fatigue type, which is initiated by the formation of cracks in the subsurface. Whereas zirconia commonly demonstrates a mode of wear consistent with adhesive or attritional wear, which happens when two surfaces slide against one another causing friction between them. ${ }^{(53)}$

In the present study; the highest antagonist enamel volume loss was recorded by f. explore followed by e. max, followed by Obsidian. This result comes in agreement with Ludovichetti et al ${ }^{(54)}$ who evaluated the wear resistance and abrasiveness of CAD-CAM materials in a two body wear test setup together with bovine enamel. They found that zirconia only caused damage to enamel substrate, whereas the lithium disilicate and the zirconia-reinforced lithium silicate caused wear to the antagonist enamel. The same author stated that hardness should be considered in the selection of materials, while the roughness and the friction coefficient of some materials might change during the wear process. Results come in accordance with researchers supporting that the lower the hardness of the restorative material the lower the enamel wear and vice versa. ${ }^{(43,55)}$ Mormann et al ${ }^{(83)}$ reported that the lower the hardness, the lower the enamel wear, which is in accordance with the present study. Therefore, a softer material is abraded more easily than harder material. ${ }^{(56)}$ Also, many researchers ${ }^{(43,44)}$ proved that ceramics with higher crystallinity are much more wear resistant than ceramics with lower crystals content and consequently they are more abrasive to the opposing.

Other properties may be valued in determining the wear potential of the materials. Wang et al ${ }^{(57)}$ described that when the mismatch of the elastic modulus and the strength between the enamel and restorative materials are large, the enamel suffers high stress concentration and, consequently, stress abrasion. They stated that the high strength and toughness of zirconia enabled it to resist surface damage under stress, keeping its fineness and 
coefficient of friction unchanged over time. In contrast, enamel suffers fatigue wear with microcrack formation and propagation in the subsurface. ${ }^{(40,58)}$ Therefore, high hardness combined with high flexural strength (1200 MPa) and elastic modulus (210 GPa) may explain the considerable wear potential of the explore. In addition, as the specimens were exposed to water during the entire experiment, the low temperature degradation of zirconia with an increase in surface roughness might have contributed to the high abrasion of the antagonists. ${ }^{(58)}$

In contrast, the elastic modulus of the IPS e.max CAD (67.2 GPa10 and $95 \mathrm{GPa}$ according to the manufacturer) was similar to that of enamel (60 to $100 \mathrm{GPa} 22$ ). Despite the differences in the composition and microstructure of the lithium disilicate (IPS e.max $\mathrm{CAD}$ ) and the zirconia-reinforced lithium silicate (Obsidian) materials, they were not statistically different concerning the properties evaluated. In addition, Belli et al ${ }^{(59)}$ reported that the Young modulus of these materials was similar. These similar properties explain the similarity in wear behavior found for IPS e.max CAD and Obsidian. Similar results were reported by Ludovichetti et al. ${ }^{(13)}$ who used two-body wear test with ACTA wear machine for 200,000 cycles and determined the wear rate with a surface profilometer. The authors did not find statistically significant differences between ZLS and LD for wear against bovine enamel.

\section{CONCLUSIONS}

Based on the findings of this in vitro study, the following conclusions were drawn:

1. Obsidian is more wear resistant than e. max and f. explore.

2. Functional explore zirconia produce more wear in opposing teeth compared with e. max while Obsidian produce the least wear in opposing enamel.

3. Obsidian was the most antagonist friendly materials when sliding against enamel.

\section{ACKNOWLEDGEMENT}

The author would like to thank Ivory Trade International Co. the dealer for Upcera Company in the Egyptian market for supplying Functional Explore zirconia disks for this research.

\section{REFERENCES}

1. Lucas PW, Omar R, Al-Fadhalah K, Almusallam AS, Henry AG, Michael S, Thai LA, Watzke J, Strait DS, Atkins AG. Mechanisms and causes of wear in tooth enamel: implications for hominin diets. J R Soc Interface 2013;10: 20120923.

2. Cekic-Nagas, I.; Ergun, G.; Egilmez, F.; Vallittu, P.K.; Lassila, L.V. Micro-shear bond strength of different resin cements to ceramic/glass- polymer CAD-CAM block materials. J. Prosthodont. Res. 2016, 60, 265- 273.

3. Gracis, S.; Thompson, V.P.; Ferencz, J.L.; Silva, N.R.; Bonfante, E.A. A new classification system for all-ceramic and ceramic-like restorative materials. Int. J. Prosthodont. 2015, 28, 227-235.

4. Denry I, Holloway JA. Ceramics for dental applications: A review. Materials 2010;3:351-68.

5. Araujo NS, Moda MD, Silva EA, Zavanelli AC, Mazaro JV, Pellizzer EP. Survival of all-ceramic restorations after a minimum follow-up of five years: A systematic review. Quintessence Int 2016;47:395-405.

6. Arsecularatne JA, Chung NR, Hoffman M. An in vitro study of the wear behaviour of dental composites. Biosurf Biotribol 2016;2:102-13.

7. Fischer TE, Anderson MP, Jahanmir S. Influence of fracture toughness on the wear resistance of yttria-doped zirconium oxide. J Am Ceram Soc 1989;72:252-7.

8. FuXia Liang1 · ChengLi Sun1 · HongYu Yang1 · EnZhu Li1 - ShuRen Zhang1. Synthesis and study of lithium silicate glass-ceramic. J Mater Sci: Mater Electron (2017) 28:15405-15410.

9. Stawarczyk B, Frevert K, Ender A, Roos M, Sener B, Wimmer T. Comparison of four monolithic zirconia materials with conventional ones: Contrast ratio, grain size, four-point flexural strength and two-body wear. J Mech Behav Biomed Mater 2016;59:128- 38.

10. Janyavula S, Lawson N, Cakir D, Beck P, Ramp LC, Burgess JO. The wear of polished and glazed zirconia against enamel. J Prosthet Dent 2013;109:22-9. 
11. Flury S, Lussi A, Zimmerli B (2010) Performance of different polishing techniques for direct CAD/CAM ceramic restorations. Oper Dent 35:470-481.

12. Mike Matzinger1 \& Sebastian Hahnel1 \& Verena Preis 1 \& Martin Rosentritt1 Polishing effects and wear performance of chairside CAD/CAM materials Clinical Oral Investigations (2019) 23:725-737.

13. Francesco Saverio Ludovichetti,Arie Werner, Flávia Zardo Trindade, Cornelis Johannes Kleverlaan and Renata Garcia Fonseca: Wear resistance and abrasiveness of CAD-CAM monolithic materials J Prosthet Dent 2018;120:318.e1-e8.

14. Nawafleh N, Hatamleh M, Elshiyab S and Mack F, Lithium Disilicate Restorations Fatigue Testing Parameters: A Systematic ReviewJournal of Prosthodontics 25 (2016) 116-126).

15. Giacomelli L, Derchi G, Frustaci A, Bruno O, Covani U, Barone A, De Santis D and Chiappelli F. Surface Roughness of Commercial Composites after Different Polishing Protocols: An Analysis with Atomic Force Microscopy The Open Dentistry Journal, 2010, 4, 191-194).

16. Kakaboura A, Fragouli M, Rahiotis C, et al. Evaluation of surface characteristics of dental composites using profilometry, scanning electron, atomic force microscopy and gloss-meter. J Mater Sci Mater Med 2007; 18: 155-63.].

17. Nathaniel C. Lawsson, Deniz cakir, and John O. Burgess:Characterization of third-body media particles and their effect on in vitro composite wear. Dent Mater. 21012 Aug;28(8)e118-e126.

18. Quinn, G.D. On edge chipping testing and some personal perspectives on the state of the art of mechanical testing. Dent. Mater. 2015, 31, 26- 36.

19. Heintze, S.D.; Cavalleri, A.; Forjanic, M.; Zellweger, G.; Rousson, V. Wear of ceramic and antagonist-A systematic evaluation of influencing factors in vitro. Dent. Mater. 2008, 24, 433-449.

20. Stawarczyk B, Özcan M, Schmutz F, Trottmann A, Roos $\mathrm{M}$, Hämmerle $\mathrm{CH}$. Two-body wear of monolithic, veneered and glazed zirconia and their corresponding enamel antagonists. Acta Odontol Scand 2013;71:102-12.

21. Phillips RW. Skinners Science of Dental Materials. 8th ed. Philadelphia: W.B Saunders Co., Harcourt Brace and Co.; 1982.

22. Heintze SD, Cavalleri A, Forjanic M, Zellweger G, Rousson V. Wear of ceramic and antagonist-a system- atic evaluation of influencing factors in vitro. Dent Mater 2008;24:433-49.

23. Elmaria A, Goldstein G, Vijayaraghavan T, Legeros RZ, Hittelman EL. An evaluation of wear when enamel is opposed by various ceramic materials and gold. J Prosthet Dent 2006;96:345-53.

24. Jung YS, Lee JW, Choi YJ, Ahn JS, Shin SW, Huh JB. A study on the in-vitro wear of the natural tooth structure by opposing zirconia or dental porcelain. J Adv Prosthodont 2010;2:111-5.

25. Scurria M, Powers J. Surface roughness of two polished ceramic materials. J Prosthet Dent 1994; 71:174-7.

26. Etman M, Woolford M, Dunne S. Quantitative measurement of tooth and ceramic wear: in vivo study, Int J Prosthodont 2008; 21:245-52.

27. Amer R, Kürklü D, Johnston W: Effect of simulated mastication on the surface roughness of three ceramic systems. J Prosth Dent, 2015; 114: 260-5.

28. Piht1l1 H, Tosun N. Investigation of the wear behavior of a glass- fiber-reinforced composite and plain polyester resin. Compos. Sci. Technol, 2002; 62: 367-70.

29. Heintze S, Cavalleri A, Forjanic M, Zellweger G, Rousson V. A comparison of three different methods for the quantification of the in vitro wear of dental materials Dent Mater 2006; 22: 1051-62.

30. Elmaria A, Goldstein G, Vijayaraghavan T, Legeros RZ, and Hittelman E L. An evaluation of wear when enamel is opposed by various ceramic materials and gold . J Prosthet Dent 2006;96:345-53.

31. Peng JY, Luo XP, Zhang L.Flexural strength and open porosity of two different veneering ceramics for zirconia framework.Int J Appl Ceram Tech. 2015;12(2):383-9.

32. Leung BT, Tsoi JK, Matinlinna JP, pow EH. Comparison of mechanical properties of three machinable ceramics with an experimental fluorophalogopite glass ceramic. J Prosthet Dent. 2015;114(3):440-6.

33. Lohbauer U, Reich S. Antagonist wear of monolithic zirconia crowns after 2 years. Clin Oral Investig 2017;21:1165-72.

34. Passos SP, Torrealba Y, Major P, Linke B, Flores-Mir C, Nychka JA. In vitro wear behavior of zirconia opposing enamel: a systematic review. J Prosthodont 2014;23:593-601.

35. Zarone F, Russo S, Sorrentino R. From porcelain -fusedto-metal to zirconia : clinical and experimental considerations .Dent Mater. 2011; 27(1): 83-96. 
36. Harrison A. Wear of combinations of acrylic resin and porcelain, on an abrasion testing machine. J Oral Rehabil 1978;5:111-5.

37. Kim M, Oh SH, Kim J, Ju S, Seo D, Jun S, Ahn J, Ryu J. Wear evaluation of the human enamel opposing different Y-TZP dental ceramics and other porcelains. J Dent 2012; 40: 979-88.

38. Preis V, Behr M, Handel G, Schneider-Feyrer S, Hahnel S, Rosentritt M. Wear performance of dental ceramics after grinding and polishing treatments. Journal of the Mechanical Behavior of Biomedical Materials 2012; 10: 13-22.

39. Fischer T, Anderson M, Jahanmir S. Influence of fracture toughness on the wear resistance of yttria-doped zirconium oxide. J Am Ceram Soc 1989; 72: 252-7.

40. Sripetchdanond J, Leevailoj C, Wear of human enamel opposing monolithic zirconia, glass ceramic, and composite resin: An in vitro study. J Prosthet Dent 2014; 112:1141-50.

41. Preis V, Weiser F, Handel G, Rosentritt M. Wear performance of monolithic dental ceramics with different surface treatments. Quintessence Int. 2013 May;44(5):393-405. doi: 10.3290/j.qi.a29151.

42. Kuretzky T, Urban M, Dittmann R, Peez R, Mecher E. Wear behavior of Zirconia compared to state-of-the-art ceramics. In: 89th IADR; 2011Mar;[Abstr. No. 1381].

43. Lawson NC, Janyavula S, Syklawer S, McLaren EA, Burgess JO. Wear of enamel opposing zirconia and lithium disilicate after adjustment, polishing and glazing. J Dent. 2014 Dec;42(12):1586-91. doi: 10.1016/j.ent.2014.09.008.

44. Albashaireh ZS, Ghazal M, Kern M. Two-body wear of different ceramic materials opposed to zirconia ceramic. J Prosthet Dent. 2010 Aug;104(2):105-13. doi:10.1016/ S0022-3913(10)60102-3.

45. Joao Paulo Mendes Tribst, Larissa Marcia Marques Alves , Amanda Maria de Oliveira Dal Piva1, , Renata Marques de Melo , Alexandre Luiz Souto Borges, Tarcisio Jose Arruda Paes-Junior, Marco Antonio Bottino Reinforced glass ceramics: Parametric Inspection of Three- Dimensional Wear and Volumetric Loss after Chewing Simulation Brazilian Dental Journal (2019) 30(5): 505-510.

46. Dal Piva AMO, Tribst JPM, Borges ALS, Souza ROAE, Bottino MA. CAD-FEA modeling and analysis of different full crown monolithic restorations. Dent Mater 2018;S0109-5641:30026-30035.
47. Lawson NC, Bansal R, Burgess JO. Wear, strength, modulus and hardness of CAD/CAM thyrestorative materials. Dent Mater 2016;32:e275-e283.

48. Wu C CM, Rice RW, Johnson D, Platt BA. Grain size dependence and R-curve effects in the abrasive wear of alumina. J Am Ceram Soc 1985; 72:1249-52.

49. Wu C CM, Rice RW. Porosity dependence of wear and other mechanical properties on fine-grain A12O3 and B4C. Ceram Eng Sci Proc 1985;6: 977-94.

50. Zum Gahr KH, Bundschuh W, Zimmerlin B. Effect of grain size on friction and sliding wear of oxide ceramics. Wear 1993;162:269-79.

51. Zum Gahr KH. Sliding wear of ceramic-ceramic, ceramicsteel and steel-steel pairs in lubricated and unlubricated contact. Wear 1989;133:1- 22.

52. Mundhe K, Jain V, Pruthi G, Shah N. Clinical study to evaluate the wear of natural enamel antagonist to zirconia and metal ceramic crowns. J ProsthetDent.2015 Sep;114(3):358-63.

53. Malgorzata Roos3 \& Christoph H. F. Hämmerle1oh Ws, DeLong R, Anusavice J. Factors affecting enamel and ceramic wear: A literature review. J Prosthe Dent 2002; 87(4): 451-9.

54. Flávia Zardo Trindade, Arie Werner, Francesco Saverio Ludovichetti, Cornelis Johannes Kleverlaan, and Renata Garcia Fonseca, Wear resistance and abrasiveness of CAD-CAM monolithic materials J Prosthet Dent 2018;120:318.e1-e8

55. Chun YL, Ngan AH, King NM. Nano-scale structure and mechanical properties of the human dentine-enamel junction. J Mech Behav Biomed Mater. 2011;4(5):785-795.

56. Shimane T, Endo K, Zheng JH, Yanagi T, Ohno H. Wear of opposing teeth by posterior composite resins-evaluation of newly developed wear test methods. Dent Mater 2010; 29:713-20.

57. Wang L, Liu Y, Si W, Feng H, Tao Y, Ma Z. Friction and wear behaviors of dental ceramics against natural tooth enamel. J Eur Ceram Soc 2012;32: 2599-606

58. Galvão Ribeiro BR, Galvão Rabelo Caldas MR, Almeida AA Jr, Fonseca RG, Adabo GL. Effect of surface treatments on repair with composite resin of a partially monoclinic phase transformed yttrium- stabilized tetragonal zirconia. J Prosthet Dent 2018;119:286-91.

59. Belli R, Wendler M, de Ligny D, Cicconi MR, Petschelt A, Peterlik H, et al. Chairside CAD/CAM materials. Part 1: Measurement of elastic constants and microstructural characterization. Dent Mater 2017;33:84- 98. 